\title{
MHealth for Decision Making Support: A Case Study of EHealth in the Public Sector
}

\author{
Majed Kamel Al-Azzam ${ }^{1}$ \\ Business Administration Department \\ Yarmouk University \\ Irbid, Jordan
}

\author{
Malik Bader Alazzam ${ }^{2}$ \\ Software Engineering Department \\ Ajloun National University \\ Jordan
}

\author{
Majida Khalid al-Manasra ${ }^{3}$ \\ Biomedical and Communication \\ Engineering, Summit International \\ Academy-Jordan
}

\begin{abstract}
This paper seeks to explore factors that determine the acceptance of the MHealth application patients. The research relied on (UTAUT2) Unified Theory of Acceptance and Use of Technology to assess the level of acceptance of a new mobile health application by patients. The study involved conducting test surveys across medical hospitals in Jordan with the goal of collecting data from hospital visitors and their patients concerning their intention to use the new mobile health application. 98 questionnaires were collected and 44 valid responses drawn from them for onward data analysis. The UTAUT2 research model was the most appropriate one for conducting the evaluation on MHealth's user acceptance. Its results would support the government's goal of building m-health solutions that meet user needs. The model also enhances the roles of DSS in facilitating adoption of MHealth applications. This study provides a theoretical framework for pursuing future research work on the rates of adoption of m-health applications by patients.
\end{abstract}

Keywords-Mobile health application; UTAUT1; UTAUT2; trust factors

\section{INTRODUCTION}

Mobile technology is growing rapidly [1][2], prompting more healthcare organisations to consider mobile health technologies to be a feasible solution for monitoring patients' status. This development has formed the possible for converting healthcare system supply into a more available, reasonable, and active form [3][4][5]. The electronic health system (e-health system) used in the traditional setting are faulted for their reliance on wired connections and computers. As an improvement, mobile health uses wireless cellular communication to achieve mobility and flexibility [6][7]. It also has the advantage of portability and long-life battery power. Due to their mobility, portability, and flexibility of mobile technologies, they are preferred over traditional systems when seeking to enhance access to healthcare services. They also help to reduce the costs and time incurred in delivering healthcare [8]. These systems may also be used to create motivation amongst healthcare professionals to stick to professional habits by reshaping [9][10]. Mobile health system is gaining increased prominence as a favoured technology on health communication. Its importance goes beyond more communication by including aspects such as management [11], facilitation and delivery of health information through monitor, cell phones, wireless infrastructure, tablets, and sensors. Mobile healthcare technologies include many healthcare services and applications such as site-based health services, mobile telemedicine, and pervasive information access to healthcare systems, and patient monitoring [12][13] [14]. They bring great benefits to both patients and physicians.

In addition the potential financial and medical additions of mobile health service area, the implementation of the use of MHA opposite tasks and walls at the social, technological, culture, governmental and governmental points, particularly in developing nations [15] [16] after interviews with Patients and reviewers and health organizations there are several barriers. one of the key notes that we observed is the lack of the cognizance about mobile health applications (MHA) [17][14] , facilities and its benefits. Second, there are concerns with act of application. Third, patients do not neediness to change the routine of providing healthcare system, equal with the probable assistances of mobile health app [17] [18] [19]. Several patients sense that physicians are so busy and do not have period to use the app to follow up and remotely display them. Fourth, there is a unlimited mission with respect to the belief, extra than one patient do not belief any administration system.

Lastly, it is hard to accept mobile health app without there is community acceptance also official support. The acceptance of mobile health system depends on several factors beyond the technology's skills. These issues include the willingness of the patients, health professionals, and care contributors to adopt embrace new technology [20][21][22][23][24]. To some extent, it also depends on the level to which the management will provide the necessary support. It is vital to remember that any role of DSS is to help support the aims of the healthcare organizations.

When creating m-health system, an institution needs to have information on the potential for its users' acceptance. In this regard, they need to rely on proper research on the established factors that influence users to adopt or reject new mobile healthcare technology [25]. This is especially important in the modern healthcare setting, as most hospitals strive to encourage the public and their staff to embrace new interventions for health promotion as a way of reducing healthcare costs and enhancing the overall health standards.

The researchers from several disciplines have been reviewing computerized DSS for around 55 years [26][27][28]. DSS frameworks can be distributed into five types including: first-Model(driven DSS), second(Data-driven 
DSS) [29][26], third Communications (driven DSS), forth Document (driven DSS), fifth Knowledge (driven DSS).

- Model driven DSS emphasize admission to and handling of economic, or simulation models. Modeldriven DSS use incomplete factors delivered by decision makers to assistance decision makers in investigating a state. Academics motivated on model management and on improving further diverse styles of models for use in DSS such as optimization, and simulation models.

- data-driven DSS give emphasis to admission to manipulation of a time series of internal establishment data and at times external, real-time data. Simple file systems accessed by query and recovery tools provide the most basic level of functionality.

- Communications-driven DSS- use system and communications technologies to enable and communication. In these systems, communication technologies are the dominant architectural factor. Tools used contain groupware. In overall, groupware, bulletin boards, audio and videoconferencing.

- Document-driven DSS- usages handling technologies to deliver document retrieval and analysis. Vast document databases may hold scanned documents, images, sounds, and video. Cases of documents that might be accessed by a document-driven DSS are rules and techniques, product specifications, corporate historical documents.

- Knowledge-driven DSS- can propose actions to managers. These DSS are person-computer systems with intensive problem-solving expertise [30][31]. The expertise involves of knowledge about an exact domain, considerate of problems inside domain.

\section{A. Review of Decision Support System in Healthcare Sector}

There are two main areas for making primary decisions in the healthcare setting. The first lower level area has to do with diagnosis and treatment, patient management, finance management, inventory and record keeping The second higher level area is meant to position the healthcare facility in a competitive place relative to its competitors [32]. In this area, some of the functions handled include patient management and inventory management. This second higher level of decision making is mostly meant to benefit shareholders, while the lower level decisions is mainly targeted to improve the work of nurses and doctors. An example of a decision support system in the healthcare setting is the PRODIGY [33]. This DSS allows healthcare professionals to access evidence and knowledge on disease symptoms and conditions when delivering primary healthcare [34]. PRODIGY is an acronym for Prescribing Rationally with Decision support In General Practice Study. The system provides full text guidance, drug information, patients information leaflets, self-help contacts, and quick reference guides to pharmacists, nurses and patients. Other important information maintained by PRODIGY include finance information such as accounts receivable, track billing, accounts payable and payroll; patient insurance policy, insurance payment options, and insurance claims.

MedSphere also offers decision support systems that have various modules [35][10]. Their systems have modules that are integrated to deliver a comprehensive functionality. They capture important information on the patient's billing as they move from registration, diagnosis, prescription, admission and discharge. It also has modules for handling collection processing, Supply chain management, and other features. It gives instantaneous view on the financial state of the hospital at any given time [7]. DSS supports patient diagnosis, as it displays patients' background information and provides clinicians with knowledge on symptoms for various health problems and their recommended treatment processes [36]. As showed in Fig. 1, clinician can use DSS to determine proper drug usage, diagnose the health problem of a patient, and send reminders to other staff to administer drugs to hospitalised patients on time. Another example of such a DSS is known as Isabel. This system has a database of medical records for patients which are accessible over the web.

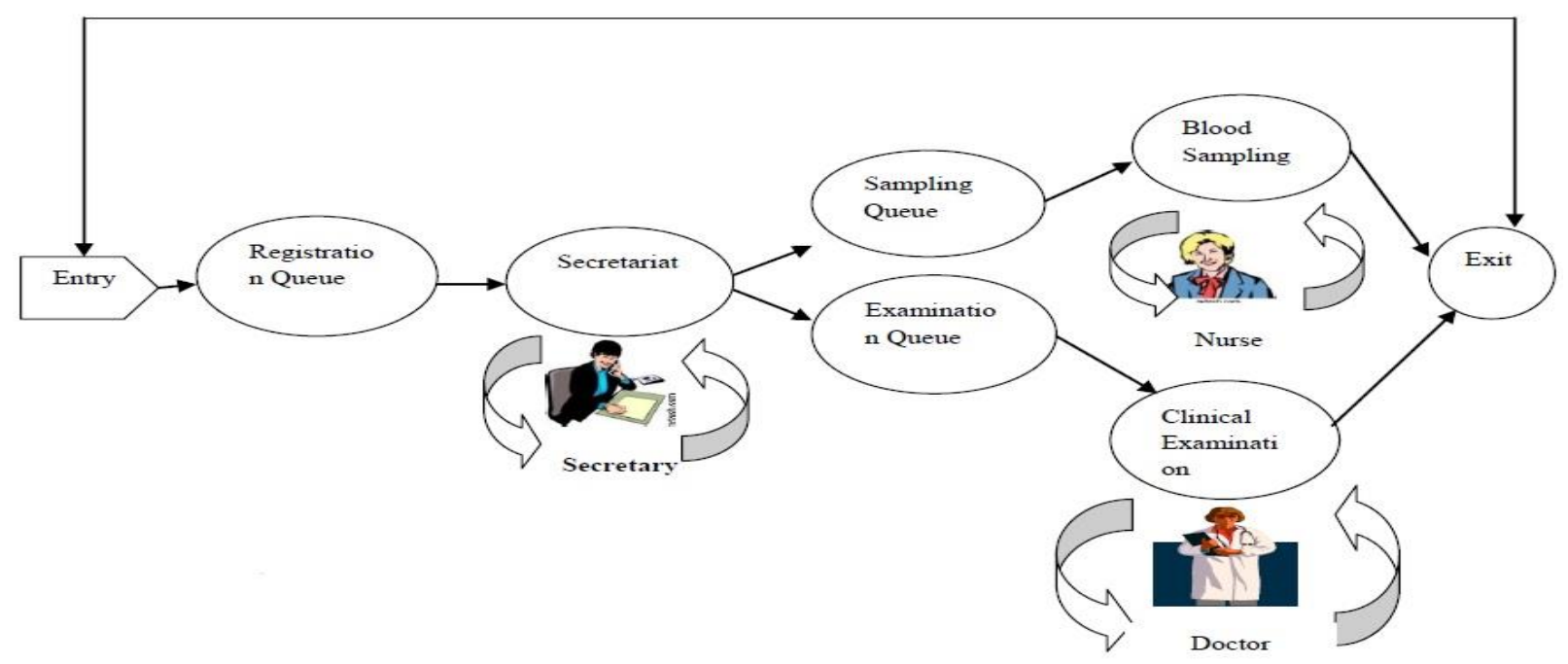

Fig. 1. DSS Progress Example [27]. 


\section{LITERATURE REVIEW}

\section{A. UTAUT1}

More research has been conducted on the technology acceptance models. Different models and theories propel these studies. The researchers of UTAUT model have identified and harmonized 8 different models and theories that form a comprehensive acceptance model. These theories are [11], [37]: Social Cognitive Theory-SCT-, Technology Acceptance Model -TAM-, Motivational Model -MM-, Theory Reason Action TRA-, and Theory of Planned Behavior- TPB, Innovation Diffusion Theory -IDT.

The unification of these studies make a summation of all the constructs from the eight models into four different determinants which help in predicting the usage, the intentions, and the specific moderators of all important relationships (Morris et al., 2003) [38]. Fig. 2 makes an illustration of the relationships inherent within the UTAUT [13][39]. This model is composed of 4 exogenous variables $(\mathrm{EV})$ that are namely; performance expectancy (PE), effort expectancy (EE), facilitating conditions (FC) and social influence (SI) [39]. These exogenous variables are mainly used in technology intention to the behavior and usage. Among these exogenous variables [38][37], there are four moderators which include age, gender, experience and voluntariness.

\section{B. UTAUT2}

The study has extended the unified theory and the technology model by examining how technology is used and accepted by consumers as shown in Fig. 3. The goals of UTAUT2 align with those of UTAUT1 and the concepts of HM, PV and HT[40]. According to this study by Venkatesh, the user's demographic characteristics became the moderator variables[41][1][40] They included experience, age, and gender; and how they affected technology use.

\section{Hedonis Motivation (HM)}

It is described as the intrinsic motivation of a user of technology [42][43][13]. It is considered critical in constructing a model to determine use and acceptance of technology. HM can be compared to playfulness or the user's enjoyment of TAM as a factor that has intrinsic value.

\section{Price Value $(P V)$}

People are known to choose the products and services that benefit them more than price value. As such [44][45], one can define price value as conscious trade-off that people make between the money costs of acquiring a new application and the perceived benefits that they would derive from the application.

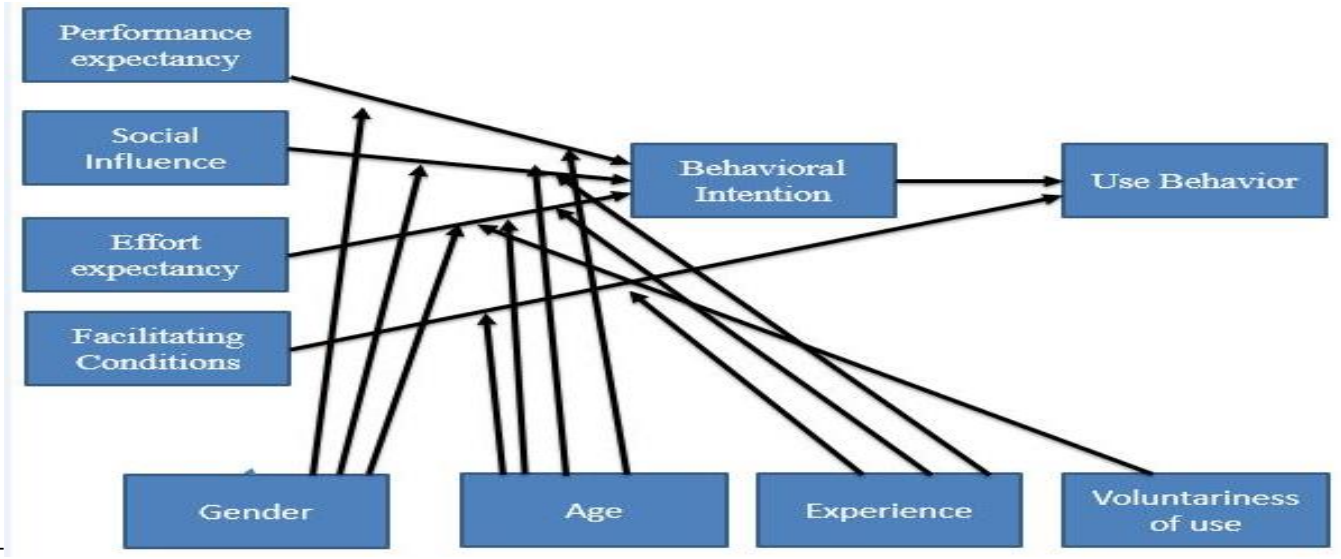

Fig. 2. UTAUT1 Model.

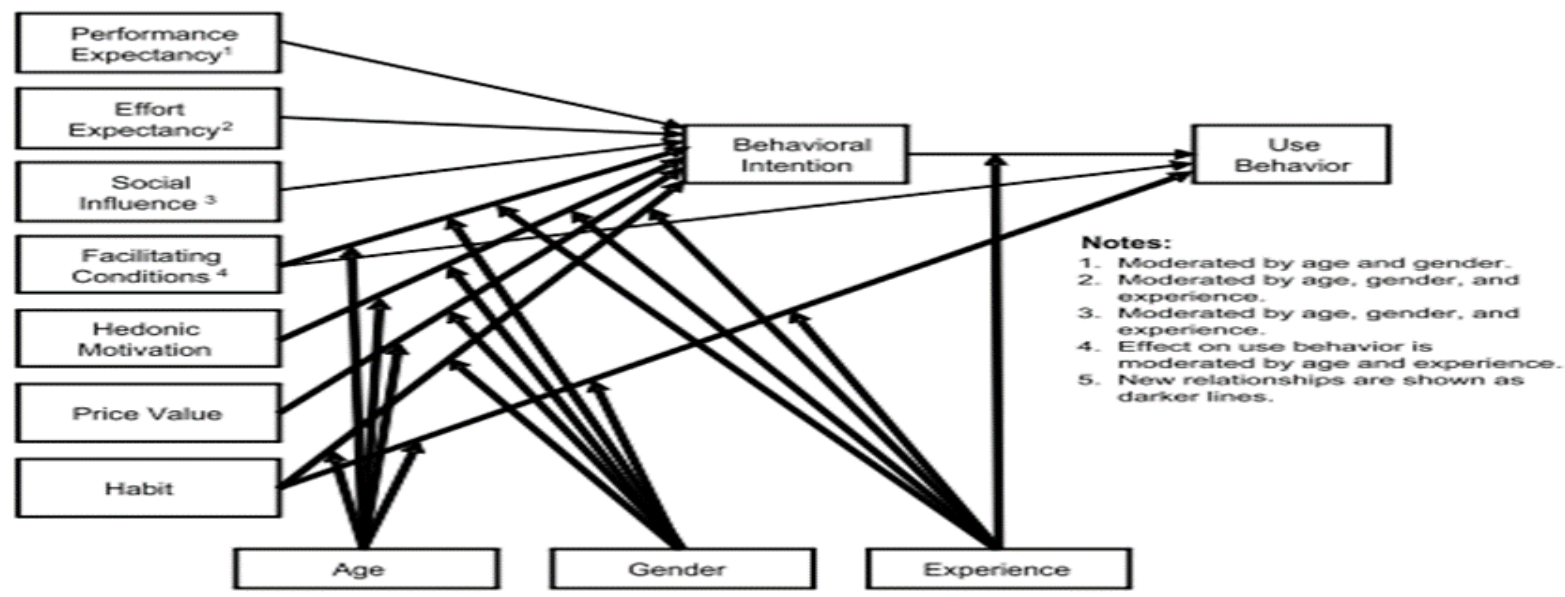

Fig. 3. UTAUT 2 Model. 


\section{E. Mobile Health Application}

EHealth-related information can be collected, stored, and exchanged effectively through a range of tools provided through various information and communication technologies (ICTs)[3]. Healthcare can harness these technologies to enhance their level of safety, quality and cost performance. MHealth is considered as one of the key applications in healthcare delivery, as it combines several functions such as telemedicine, electronic prescription, test ordering, emergency information and digital imaging. These elements help the healthcare professionals to obtain medical evidence in a reliable manner. Such evidence supports the healthcare organizations in delivering their clinical mandate. MHealth application also enhances service delivery and organisational efficiency in the healthcare setting. Different healthcare stakeholders such as professionals, patients, general public and organizations can use the MHealth application[46]. Different studies indicate that MHealth applications bring great benefit to patients. One such benefit is that it raises the quality of care by providing easy access to important health data that a patient may need from different health service providers. Most MHealth applications are also modelled to support disease management programs that bring great benefit to patients.

Table I summarises related studies on the topic of user's intention to adopt new MHealth applications.

TABLE I. MHEALTH APPLICATION REVIEW

\begin{tabular}{|c|c|c|c|c|c|}
\hline Author & Description & Origin & Method, sample size & Model & Results \\
\hline [19] & $\begin{array}{l}\text { Examines the user } \\
\text { adoption of a new } \\
\text { tablet application that } \\
\text { aims to provide } \\
\text { support for cognitive } \\
\text { stimulation for the } \\
\text { elderly }\end{array}$ & Paris & , survey, 15 senior users & $\begin{array}{l}\text { Cognitive } \\
\text { Therapy }\end{array}$ & $\begin{array}{l}\text { good acceptability of the app's games } \\
\text { that continues and improves with time }\end{array}$ \\
\hline$[47]$ & $\begin{array}{l}\text { Applying an } \\
\text { Acceptance Model to } \\
\text { assess the adoption of } \\
\text { M-Health Services by } \\
\text { health related users in } \\
\text { UAE }\end{array}$ & UAE & Survey , 144 & (TAM) & $\begin{array}{l}\text { model. PU, PEOU, TR and SE found } \\
\text { directly influencing the intention to } \\
\text { use M-Health system }\end{array}$ \\
\hline$[9]$ & $\begin{array}{l}\text { Achieving privacy and } \\
\text { security in MHealth } \\
\text { applications }\end{array}$ & USA, EU & Review and Recommendations & $\begin{array}{l}\text { Review and } \\
\text { Recommendations }\end{array}$ & \\
\hline [16] & $\begin{array}{l}\text { Assessing the current } \\
\text { state of the art in } \\
\text { mobile health-related } \\
\text { and clinical apps }\end{array}$ & $\begin{array}{l}\text { USA, } \\
\text { Europe, }\end{array}$ & brief survey of evaluation studies & $\begin{array}{l}\text { evaluation, } \\
\text { regulation and } \\
\text { certification, } \\
\text { quality }\end{array}$ & $\begin{array}{l}\text { Interactions may require substantial } \\
\text { effort. }\end{array}$ \\
\hline \multirow[t]{2}{*}{ [48] } & & $\begin{array}{l}\text { Developing } \\
\text { Countries }\end{array}$ & CASE STUDY & $\begin{array}{l}\text { capacity for } \\
\text { improved access }\end{array}$ & RECOMANDATIONS \\
\hline & $\begin{array}{l}\text { consumer's } \\
\text { acceptance of mobile } \\
\text { technology }\end{array}$ & $\begin{array}{l}\text { Egypt and } \\
\text { Yemen }\end{array}$ & 302 survey & (TAM) & $\begin{array}{l}\text { Positively Resistance to change, } \\
\text { Technology anxiety factors }\end{array}$ \\
\hline [12] & $\begin{array}{l}\text { Creating a summary } \\
\text { of } 7 \text { strategies for } \\
\text { conducting evaluation } \\
\text { and selection of } \\
\text { health-related apps: }\end{array}$ & & Interview .1 & Case study & \\
\hline [26] & $\begin{array}{l}\text { Developing and } \\
\text { performing user } \\
\text { evaluation for a } \\
\text { mobile DSS running } \\
\text { on iOS known as } \\
\text { OphthalDSS }\end{array}$ & Spain & Survey, 50 physicians answered & $\begin{array}{l}\text { Quality, Ease of } \\
\text { Use, Availability, } \\
\text { Performance }\end{array}$ & $\begin{array}{l}\text { Positively Quality, Ease of Use, } \\
\text { Availability, Performance }\end{array}$ \\
\hline
\end{tabular}




\section{RESEARCH METHODS AND RESUlTS}

\section{A. Pilot Study for MHealth Application by UTAUT2}

Quantitative research methods were used for primary research in this study. This approach helps to generate contextual information on user acceptance for MHealth applications across Jordan. It will also give background information on the use of UTAUT2 in the assessment of user acceptance for new technology [34][49]. The research will also use a correlational study design to determine whether the conceptual model has any relationships that can be interpreted as independent variables and dependent variables [6]. The section below describes the detail of the phases used in the study. 9 constructs from the technology acceptance model were measured using 32 items by following the guidelines UTAUT2. The study also involved the collection of the necessary demographics on the number of users that had embraced the new M-health application across Jordan. The demographics were intended for use in comparing different levels of user acceptance for MHealth applications in hospitals across Jordan [50]. The study recognised that the adoption of information technology is largely connected to most business activities and services.

TABLE II. SAMPLES DEMOGRAPHIC

\begin{tabular}{|l|l|l|l|}
\hline Variable & Description & Frequency & Percentage \\
\hline \multirow{3}{*}{ Gender } & aale & 28 & $63.6 \%$ \\
\cline { 2 - 4 } & Female & 16 & $36.4 \%$ \\
\hline \multirow{4}{*}{ Age } & $21-30$ & 6 & 13.65 \\
\cline { 2 - 4 } & $31-40$ & 14 & $31.80 \%$ \\
\cline { 2 - 4 } & $41-50$ & 20 & $45.50 \%$ \\
\cline { 2 - 4 } & $51-60$ & 4 & $9.10 \%$ \\
\hline
\end{tabular}

TABLE III. VARIABLES

\begin{tabular}{|c|c|c|c|c|c|c|}
\hline $\begin{array}{l}\text { Variable } \\
\text { Group }\end{array}$ & $\begin{array}{l}\text { No. } \\
\text { Items }\end{array}$ & Item & Min & Max & Mean & $\begin{array}{l}\text { Std. } \\
\text { Deviation }\end{array}$ \\
\hline \multirow{4}{*}{$\begin{array}{l}\text { Performance } \\
\text { expectancy }\end{array}$} & \multirow{4}{*}{4} & I would find MHEALTH (useful) in my job & 2.00 & 5.00 & 4.0554 & .89853 \\
\hline & & Using MHEALTH (increases) my chances of achieving things that are vital to me & 2.00 & 5.00 & 3.5455 & 1.22386 \\
\hline & & Using MHEALTH aids me accomplish things more rapidly. & 1.00 & 5.00 & 3.8081 & .97145 \\
\hline & & Using MHEALTH in my job & 2.00 & 5.00 & 3.6818 & 1.39340 \\
\hline \multirow{4}{*}{$\begin{array}{l}\text { Effort } \\
\text { Expectancy }\end{array}$} & \multirow{4}{*}{4} & Learning to operate MHEALTH app would be relaxed & 1.00 & 5.00 & 3.8081 & 1.30600 \\
\hline & & My interaction with MHEALTH app is clear & 1.00 & 5.00 & 3.7708 & 1.42716 \\
\hline & & I find MHEALTH app easy to use & 1.00 & 5.00 & 3.5455 & 1.40500 \\
\hline & & It is relaxed for me to develop expert at using MHEALTH application & 1.00 & 5.00 & 3.7702 & 1.46828 \\
\hline \multirow{3}{*}{$\begin{array}{l}\text { Social } \\
\text { Influence }\end{array}$} & \multirow{3}{*}{3} & Persons who are significant to me reflect that I should use MHEALTH application & 1.00 & 5.00 & 3.2044 & 1.21052 \\
\hline & & Persons who effect my behaviour think to use MHealth application & 1.00 & 5.00 & 3.2201 & 1.27920 \\
\hline & & Persons whose views that $\mathrm{x}$ value select that I use MHEALTH application & 1.00 & 5.00 & 3.6601 & 1.16217 \\
\hline \multirow{4}{*}{$\begin{array}{l}\text { Facilitating } \\
\text { condition }\end{array}$} & \multirow{4}{*}{4} & I have the resources essential to use MHEALTH & 1.00 & 5.00 & 3.5909 & 1.05375 \\
\hline & & I have the knowledge needed to use MHEALTH & 1.00 & 5.00 & 3.9545 & .89853 \\
\hline & & MHEALTH is compatible with other tools I use & 1.00 & 5.00 & 3.5213 & 1.00755 \\
\hline & & get help from experts when I have problems using MHEALTH application & 1.00 & 5.00 & 3.4440 & 1.29685 \\
\hline \multirow{3}{*}{$\begin{array}{l}\text { Hedonic } \\
\text { Motivation }\end{array}$} & \multirow{3}{*}{3} & MHealth application is so fun. & 1.00 & 5.00 & 3.0114 & 1.42413 \\
\hline & & MHealth application is so enjoyable & 1.00 & 5.00 & 3.0124 & 1.31590 \\
\hline & & MHealth application is so entertaining. & 1.00 & 5.00 & 2.8541 & 1.46311 \\
\hline \multirow{3}{*}{ Price Value } & \multirow{3}{*}{3} & MHEALTH application is judiciously priced & 1.00 & 4.00 & 3.4471 & 1.21677 \\
\hline & & MHEALTH application is a not bad value for the money & 1.00 & 5.00 & 3.8854 & 1.46015 \\
\hline & & existing price, MHealth application provides a respectable value & 1.00 & 5.00 & 3.6547 & 1.54863 \\
\hline \multirow{4}{*}{ Habit } & \multirow{4}{*}{4} & use of MHEALTH application has become a nice and habit & 1.00 & 5.00 & 3.4401 & 1.09801 \\
\hline & & I am addicted to using MHealth app & 1.00 & 5.00 & 3.8801 & 1.13294 \\
\hline & & I must use MHealth app & 1.00 & 5.00 & 3.3182 & 1.21052 \\
\hline & & Using MHealth app has become natural to me & 2.00 & 5.00 & 4.0014 & 1.15470 \\
\hline \multirow{3}{*}{ Behaviour } & \multirow{3}{*}{3} & I plan to remain using MHealth app in the future & 1.00 & 5.00 & 3.2014 & 1.17422 \\
\hline & & I will continuously try to use MHealth app in my daily life & 1.00 & 5.00 & 3.8824 & 1.34277 \\
\hline & & I plan to continue to use MHealth app frequently & 1.00 & 5.00 & 3.7547 & 1.24924 \\
\hline \multirow{3}{*}{$\begin{array}{l}\text { Intention to } \\
\text { use }\end{array}$} & \multirow{3}{*}{3} & I frequently used MHEALTH app to understand health problem & 1.00 & 5.00 & 3.4401 & 1.24924 \\
\hline & & I often use MHEALTH app to serve patient & 2.00 & 5.00 & 3.8792 & 1.21677 \\
\hline & & I often use MHEALTH app to establish information about health issues problem & 2.00 & 5.00 & 3.8821 & 1.20317 \\
\hline
\end{tabular}


TABLE IV. CRONBACH ALPHA

\begin{tabular}{|l|l|l|l|}
\hline Variables & N of (Items) & N of delete (items) & Cronbach C Alpha A(CA) \\
\hline Performance P expectancy E (PE) & 4 & 0 & 0.91 \\
\hline Effort Expectancy(EE) & 4 & 0 & 0.901 \\
\hline Social Influence(SI) & 3 & 0 & 0.875 \\
\hline Facilitating condition(FC) & 4 & 0 & 0.876 \\
\hline Hedonic Motivation(HM) & 3 & 0 & 0.952 \\
\hline Price value(PV) & 3 & 0 & 0.932 \\
\hline Habit(H) & 4 & 0 & 0.876 \\
\hline Behaviour(B) & 3 & 0 & 0.941 \\
\hline Intention to use(IU) & 3 & 0 & 0.917 \\
\hline
\end{tabular}

The study identified 8 important success factors that researchers need to look out for when using the UTAUT2 model. These include Hedonic Motivation, Performance Expectancy, Social Influence, Effort Expectancy, Price Value, Habit, Facilitating Conditions, and Behavior. In light of this model, the researcher sought to use the Acceptance and Use of Technology approach to assess the perception that hospital visitors and patients have about the use of MHealth applications. More than 70 users participated in the survey that sought to examine their intention to use MHealth applications. The users were drawn from two major hospitals across Jordan[51][7][43][52]. The total number of valid responses collected from the survey was 44. This information is presented in Table II. Most of the valid responses were submitted by women (63.6\%) rather than men $(36.4 \%)$. Table III presented the min and max and mean of valid variables. And Table IV showed the Cronbach Alpha values.

\section{B. Reliability Test}

A reliability test was conducted in this study to measure the validity or acceptability of the measures. Cronbach's alpha test was used to determine the degree of internal consistency in the data. It sought to ascertain that the data used in the study had an appropriateness value of above 0.7 (Sekaran 2003). The results in this test indicate that the data met the basic threshold for internal consistency and the other factors used in the study were reliable.

\section{CONCLUSION AND LIMITATION}

More developing countries continue to adopt m-health applications as a critical technology that would drive a positive change in their healthcare services delivery approach. It is required to know the questions that affect related health users to approve or reject mobile health system. This research presented a model for MHA acceptance founded on UTAUT2 and explored the rationale of technology adoption for users in the mobile health system. This model united cultural, social, technological, political, and structural sides. DSS is important in conducting medical diagnosis, as it documents information on health problems and patients' background information that can be used by clinicians to quickly identify a patient's specific ailments. Limitation of this study this study have been conducted in two Jordan hospitals only. Researchers only measured trust factors and UTAUT factors. This sets a foundation for future research on patients' adoption of MHealth applications.

\section{ACKNOWLEDGMENT}

This research is funded by the Deanship of Scientific Research and Graduate Studies in Yarmouk University, Jordan.

\section{REFERENCES}

[1] M. B. Alazzam, Y. M. Al-sharo, and M. K. Al-, "Developing ( UTAUT 2 ) Model of Adoption Mobile Health Application in Jordan eGovernment," J. Theor. Appl. Inf. Technol. 30th, vol. 96, no. 12, 2018.

[2] A. M. B. Al-azzam, Majed Kamel, "Smart City and Smart-Health Framework, Challenges and Opportunities," Int. J. Adv. Comput. Sci. Appl., vol. 10, no. 2, pp. 171-176, 2019.

[3] M. Technologies, S. D. Impact, and M. I. Usage, "Mobile Technologies and Services Development Impact on Mobile Internet Usage in Latvia «Mobile Technologies and Services Development Impact on Mobile Internet Usage in Mobile Technologies and Services Development Impact on Mobile Internet Usage in Latvia," 2013.

[4] A. Dashti, I. Benbasat, and A. Burton-jones, "Working Papers on Information Systems Trust, Felt Trust, and E-Government Adoption : A Theoretical Perspective," vol. 10, no. 2010.

[5] A. Spring, A. Sukkar, and A. World, "Mobile Crowdsourcing Technology Acceptance and use in the Crises Management of Arab Spring Societies," no. June, pp. 901-910, 2014.

[6] J. Lee and M. J. Rho, "Perception of Influencing Factors on Acceptance of Mobile Health Monitoring Service: A Comparison between Users and Non-users.," Healthc. Inform. Res., vol. 19, no. 3, pp. 167-76, Sep. 2013.

[7] L. Eljawad, R. Aljamaeen, M. K. Alsmadi, I. Al-marashdeh, and H. Abouelmagd, "Arabic Voice Recognition Using Fuzzy Logic and Neural Network 1," vol. 14, no. 3, pp. 651-662, 2019.

[8] H. Cicibas and T. Internet, "Current and Emerging mHealth Technologies," pp. 283-302, 2018.

[9] I. De, T. Díez, M. Lopez-coronado, and M. López-coronado, "Privacy and Security in Mobile Health Apps: A Review and Recommendations Privacy and Security in Mobile Health Apps: A Review and Recommendations," no. October 2017, 2014.

[10] Y. Mohammad Al-Sharo, G. Shakah, M. Sh Alkhaswneh, B. Zeyad Alju-Naeidi, and M. Bader Alazzam, "Classification of big data: machine learning problems and challenges in network intrusion prediction,” Int. J. Eng. Technol., vol. 7, no. 4, pp. 3865-3869, 2018.

[11] M. Doheir, B. Hussin, A. Samad, H. Basari, and M. B. Alazzam, "Structural Design of Secure Transmission Module for Protecting Patient Data in Cloud-Based Healthcare Environment," Middle-East J. Sci. Res., vol. 23, no. 12, pp. 2961-2967, 2015.

[12] S. Mullen and S. Pagoto, "Evaluating and selecting mobile health apps: strategies for healthcare providers and healthcare organizations," no. May 2012, 2017.

[13] M. B. Alazzam, "Physicians' Acceptance of Electronic Health Records Exchange: An Extension of the with UTAUT2 Model Institutional Trust,” Adv. Sci. Lett., vol. 21, pp. 3248-3252, Feb. 2015.

[14] S. Vongjaturapat, "Mobile Technology Acceptance for Library Information Service : A Theoretical Model," pp. 290-292, 2013. 
[15] L. M. Telefons, "Mobile Technologies and Services Development Impact on Mobile Internet Usage in Latvia," vol. 1142, 2013.

[16] M. N. K. Boulos, A. C. Brewer, C. Karimkhani, D. B. Buller, and P. Robert, "Mobile medical and health apps: state of the art, concerns, regulatory control and certification," vol. 5, no. 3, pp. 1-23, 2014.

[17] C. Y. Tang, C. C. Lai, C. W. Law, M. C. Liew, and V. V. Phua, "Examining key determinants of mobile wallet adoption intention in Malaysia: an empirical study using the unified theory of acceptance and use of technology 2 model,” Int. J. Model. Oper. Manag., vol. 4, no. 3, pp. 248-265, 2014.

[18] R. Breitschwerdt, R. Iedema, S. Robert, A. Bosse, and O. Thomas, "Health Information Technology in the International Context," Adv. Health Care Manag., vol. 12, pp. 171-187, 2012.

[19] M. Yasini and G. Marchand, "Adoption and Use of a Mobile Health Application in Older Adults for Cognitive Stimulation," 2016.

[20] L. Wang, "The Important of Enjoyment and Mobility for Continuance with Mobile Data Services," 2014.

[21] A. H. H. M. Mohamed, H. Tawfik, D. Al-Jumeily, and L. Norton, "MoHTAM: A Technology Acceptance Model for Mobile Health Applications,” 2011 Dev. E-systems Eng., pp. 13-18, Dec. 2011.

[22] A. H. H. M. Mohamed, H. Tawfik, L. Norton, and D. Ai-jumeily, "Does e-Health technology design affect m-Health informatics acceptance? A case study using a particular system would enhance his or her job," vol. 25, no. C, pp. 968-971, 2012.

[23] K. M. Unertl, K. B. Johnson, and N. M. Lorenzi, "Health information exchange technology on the front lines of healthcare: workflow factors and patterns of use.," J. Am. Med. Inform. Assoc., vol. 19, no. 3, pp. 392-400, 2012.

[24] T. R. Campion, A. M. Edwards, S. B. Johnson, and R. Kaushal, "Health information exchange system usage patterns in three communities: practice sites, users, patients, and data.," Int. J. Med. Inform., vol. 82, no. 9, pp. 810-20, Sep. 2013.

[25] M. Russell and J. M. Brittain, "Health informatics," vol. 36, no. Monograph, pp. 591-628, 2002.

[26] I. De et al., "mHealth App for iOS to Help in Diagnostic Decision in Ophthalmology to Primary Care Physicians mHealth App for iOS to Help in Diagnostic Decision in Ophthalmology to Primary Care Physicians," no. October, 2017.

[27] K. Rajalakshmi and S. C. Mohan, "Decision Support System in Healthcare Industry," vol. 26, no. 9, pp. 42-44, 2011.

[28] A. Wolfenden, "Factors Predicting Oncology Care Providers" Behavioral Intention To Adopt Clinical Decision Support Systems," no. January, 2012.

[29] "An Empirical Analysis of Citizens 'Acceptance Decisions of Electronic-Government Services : A Modification of the Unified Theory of Acceptance and use of Technology (UTAUT) Model to Include Trust as a basis for Investigation by Lawrence J . Awuah RICHA," 2012.

[30] Y. Arshad and A. R. Ahlan, "Understanding ITO decisions and implementations in Malaysia public healthcare sector: The evidence from a pilot case study,” 2011 Int. Conf. Res. Innov. Inf. Syst., pp. 1-6, Nov. 2011.

[31] M. Sambasivan, P. Esmaeilzadeh, N. Kumar, and H. Nezakati, "Intention to adopt clinical decision support systems in a developing country: effect of physician's perceived professional autonomy, involvement and belief: a cross-sectional study.," BMC Med. Inform. Decis. Mak., vol. 12, no. 1, p. 142, Jan. 2012.

[32] M. B. Alazzam, "A Proposed Framework to Investigate the User Acceptance of Personal Health Records in Malaysia using UTAUT2 and PMT," Int. J. Adv. Comput. Sci. Appl., vol. 8, no. 3, pp. 386-392, 2017.

[33] M. B. Alazzam, "A Proposed Framework to Investigate the User Acceptance of Personal Health Records in A Proposed Framework to
Investigate the User Acceptance of Personal Health Records in Malaysia using UTAUT2 and PMT," Int. J. Adv. Comput. Sci. Appl., no. March, 2017.

[34] M. R. Ramli, Z. A. Abas, M. I. Desa, Z. Z. Abidin, and M. B. Alazzam, "Enhanced convergence of Bat Algorithm based on dimensional and inertia weight factor," J. King Saud Univ. - Comput. Inf. Sci., 2018.

[35] L. Carter and V. Weerakkody, "E-government adoption: A cultural comparison,” Inf. Syst. Front., vol. 10, no. 4, pp. 473-482, 2008.

[36] A. Karahoca, D. Karahoca, and M. Aksöz, "Examining intention to adopt to internet of things in healthcare technology products," Kybernetes, vol. 47, no. 4, pp. 742-770, 2018.

[37] M. B. Alazzam, A. Samad, H. Basari, and A. S. Sibghatullah, "Trust in stored data in EHRs acceptance of medical staff: using UTAUT2," Int. J. Appl. Eng. Res., vol. 11, no. 4, pp. 2737-2748, 2016.

[38] S. M.Alazzam, BASARI, "EHRs Acceptance in Jordan Hospitals By UTAUT2 Model: Preliminary Result,” J. Theor. Appl. Inf. Technol., vol. 3178, no. 3, pp. 473-482, 2015.

[39] M. Rasmi, M. B. Alazzam, M. K. Alsmadi, A. Ibrahim, R. A. Alkhasawneh, and S. Alsmadi, "Healthcare professionals ' acceptance Electronic Health Records system: Critical literature review (Jordan case study ) Healthcare professionals ' acceptance Electronic Health Records system : Critical literature review ( Jordan case study )," Int. J. Healthc. Manag., vol. 0, no. 0, pp. 1-13, 2018.

[40] A. S. MB.Alazzam, "Review of Studies With Utaut As Conceptual Framework,” Eur. Sci. J., vol. 10, no. 3, pp. 249-258, 2015.

[41] S. Yang, "Understanding Undergraduate Students' Adoption of Mobile Learning Model: A Perspective of the Extended UTAUT2," J. Converg. Inf. Technol., vol. 8, no. 10, pp. 969-979, May 2013.

[42] E. L. Slade and M. Williams, "An extension of the UTAUT 2 in a healthcare context An extension of the UTAUT 2 in a healthcare context," 2013.

[43] M. B. Alazzam, A. B. D. Samad, H. Basari, and A. Samad, "PILOT STUDY OF EHRS ACCEPTANCE IN JORDAN HOSPITALS BY UTAUT2," vol. 85, no. 3, 2016.

[44] G. Rodrigues, J. Sarabdeen, and S. Balasubramanian, "Factors that Influence Consumer Adoption of E-government Services in the UAE: A UTAUT Model Perspective," J. Internet Commer., vol. 15, no. 1, pp. 18-39, 2016.

[45] F. Fares, A. Mashagba, and M. Othman, "Modified UTAUT Model to Study the Factors Affecting the Adoption of Mobile Banking in Jordan," Int. J. Sci. Basic Appl. Res., pp. 83-94, 2012.

[46] M. El-wajeeh, "Technology Acceptance Model for Mobile Health Systems 1, 2, 3," vol. 1, no. 1, pp. 21-33, 2014.

[47] C. Paper, "Technology Acceptance Model for the Use of M- Health Services among Health Related Users in UAE," no. December, 2015.

[48] P. N. Mechael, "The Case for mHealth in Developing Countries," pp. 103-118, 2009.

[49] M. B. Alazzam, "Theories and factors applied in investigating the user acceptance towards personal health records : Review study Theories and factors applied in investigating the user acceptance towards personal health records : Review study," Int. J. Healthc. Manag., vol. 0, no. 0, pp. $1-8,2017$.

[50] M. Ally and M. Gardiner, "The moderating influence of device characteristics and usage on user acceptance of Smart Mobile Devices," no. 2010, pp. 1-10, 2012.

[51] A. A. Alalwan, A. M. Baabdullah, N. P. Rana, K. Tamilmani, and Y. K. Dwivedi, "Examining adoption of mobile internet in Saudi Arabia: Extending TAM with perceived enjoyment, innovativeness and trust," Technol. Soc., vol. 55, pp. 100-110, 2018.

[52] M. B. Alazzam, "Factors Influencing Medical Professional Adoption of Electronic Health Record in Jordan Hospital," UTeM University, 2017. 